\begin{tabular}{|c|l|}
\hline Title & The treehopper's helmet is not homologous with wings (Hemiptera: Membracidae) \\
\hline Author(s) & Y OSHIZAWA, KAZUNORI \\
\hline Citation & $\begin{array}{l}\text { Systematic Entomology, 37(1), 2-6 } \\
\text { https:/doi.org/10.1111j.1365-3113.2011.00606.x }\end{array}$ \\
\hline Issue Date & 2012-01 \\
\hline Doc URL & http://hdl.handle.net/2115/52009 \\
\hline Rights & The definitive version is available at www.blackwell-synergy.com \\
\hline Type & article (author version) \\
\hline File Information & sysent2011_treehopper.pdf \\
\hline
\end{tabular}

Instructions for use 
To be published in Systematic Entomology

OPINION

\section{Treehopper's helmet is not homologous with wings (Hemiptera: Membracidae)}

Kazunori Yoshizawa

Systematic Entomology, Graduate School of Agriculture, Hokkaido University, Sapporo, 060-8589 Japan

psocid@res.agr.hokudai.ac.jp

Tel: +81-11-706-2424

Fax: +81-11-706-4939

The helmet-like structure of membracid treehoppers (Hemiptera: Membracidae) has long been recognized as the modified tergum of the first thoracic segment (T1) (Buckton, 1903; Kramer, 1950; Hasenoehrl \& Cook, 1965; Boulard, 1973; Rietschel, 1987; Stegmann, 1998). In challenging this widely accepted interpretation Prud'homme et al. (2011) proposed a novel hypothesis: that the helmet is homologous with the wings of T1. No extant winged insects possess T1 wings; these structures apparently have been suppressed for over $250 \mathrm{Ma}$ (e.g., Grimaldi \& Engel, 2005). Morphological, developmental and gene expression evidence purported to support the helmet-wing hypothesis. The presence of a jointed articulation between the helmet and T1, analogous to the wing base joint, was considered as key evidence (Prud'homme et al., 2011).

"Wing Base" is a keyword of my research (e.g., Yoshizawa \& Saigusa, 2001; Yoshizawa, 2011) so I read Prud'homme et al., 2011 with great interest. However, I realized immediately that the 
morphological interpretations were problematic, and concluded that the interpretation of the treehopper's helmet as the modified T1 tergum should be maintained. Here I point out the problems in the morphological interpretations of Prud'homme et al. (2011) based on published data and my morphological examination of Publilia modesta, the treehopper analyzed by Prud'homme et al. (2011). Comparison was also made with a closely related but less specialized insect, a leafhopper (Pagaronia sp.).

\section{The published data}

The insect wing has two joints with the body trunk, dorsally with the tergum and ventrally with the pleuron (e.g., Snodgrass, 1935; Matsuda, 1970; Brodsky, 1994). The tergum or fused tergum + pleuron of the non-wing bearing postcephalic segments ( $\mathrm{T} 1$ and abdominal tergites) also has a ventral joint (e.g., Snodgrass, 1935). Therefore, the presence of the "ventral" joint cannot support the Prud'homme et al. hypothesis. Evidence for the "dorsal" joint between the helmet and T1 tergum thus is crucial to corroborate their interpretation. A ventral membranous joint between the helmet and the forecoxa (fig. $2 \mathrm{f}$ arrow, suppl. figs $2 \mathrm{f}, 5 \mathrm{~cd}$ ) and a dorsal muscular connection between the helmet and tergum (fig. $2 \mathrm{f}$ asterisk) are claimed. The critical point, therefore, is the interpretation of the "dorsal" connection between the helmet and tergum. However, this connection actually represents the intersegmental connection between $\mathrm{T} 1$ and $\mathrm{T} 2$ and thus cannot be homologous with the wing joint.

In the majority of Paraneoptera (a subgroup of Pterygota: Neoptera composed of Psocodea, Thysanoptera and Hemiptera, to which treehoppers belong), the anterior region of dorsal T2 (mesoscutum) is divided into three lobes by the parapsidal suture (Fig. 1A,C) (e.g., Kramer, 1950; Matsuda, 1970; Brodsky, 1994; Yoshizawa, 2005). The dorsal T2 of Publilia is divided into three lobes (Buckton, 1903; Kramer, 1950; Hasenoehrl \& Cook, 1965), as shown in Fig. 1A, matching the ground plan of Paraneoptera (Fig. 1C). In comparison with Fig. 1B, D, evidently the structure highlighted in gray is homologous and belongs to T2. This homology is supported consistently by skeletal (Buckton, 1903; Kramer, 1950; Hasenoehrl \& Cook, 1965; Boulard, 1973; Stegmann, 1998) and musculature morphology (Kramer, 1950; Burrows, 2007). Evidently Prud'homme et al. (2011) 
have misinterpreted this as T1 (fig. 2e).

This misinterpretation is evident also from the cross-sectioned specimen. In the cross-section of Publilia (fig. 2fg and suppl. fig. 2f: Prud'homme et al., 2011), well-developed longitudinal dorsal muscles can be seen. These muscles power the wing downstroke, and thus develop only in segments with functional wings (e.g., Brodsky, 1994). The longitudinal dorsal muscles are inserted onto the T2 anterior lobe (Kramer, 1950; Brodsky, 1994; Burrows, 2007) (Fig. 1). Therefore, the presence of well-developed longitudinal dorsal muscles in Prud'homme et al. fig. $2 \mathrm{f}$ shows clearly that the T2 anterior lobe of Publilia is strongly expanded anteriorly, providing further support for the homology identification shown in Fig. 1.

There seems little doubt that the helmet belongs to T1, but Prud'homme et al. have misinterpreted a part of $\mathrm{T} 2$ as $\mathrm{T} 1$. The "dorsal connection" between the helmet and tergum in Prud'homme et al. (2011) actually represents the intersegmental connection between the helmet (T1 tergum) and T2 tergum (fig. 2f asterisk: Prud'homme et al., 2011). This cannot be homologized with the wing base joint.

The misinterpretation of the wing hinge sclerites must also be noted. The wing hinge sclerites occupy the area of the dorsal wing joint (Matsuda, 1970; Brodsky, 1994; Yoshizawa \& Saigusa, 2001). By contrast, the wing hinge sclerite in Prud'homme et al. is located between the helmet and T2 (suppl. fig. 5c,d of Prud'homme et al., 2011; Figs 1D, 2 white arrowhead). Moreover, the sclerite is tightly associated with the T2 spiracle (suppl. fig. 5d of Prud'homme et al., 2011; Figs 1D, 2 black arrowhead), which demonstrates that it belongs to $\mathrm{T} 2$ and cannot be homologous with the wing hinge sclerites (Kramer, 1950).

In summary, the morphological evidence supporting the hypothesis of Prud'homme et al. (2011) cannot be substantiated, based on a review of published data alone.

\section{Morphology of the helmet}

Extensive comparative morphology is far beyond the scope of this contribution, so a single comparison was made with a leafhopper (Cicadellidae: Pagaronia sp.). Cicadellidae are considered to 
be close relatives of Membracidae (Cryan, 2005), but with a less modified T1.

First, comparison was made using the longitudinal section (Fig. 3). The dorsal helmet wall of Publilia is strongly sclerotized, projecting anteriorly over the vertex, then strongly bent posteriorly; it is continuous with the head capsule via the neck membrane. The ventral wall is membranous and continuous with T2 via the intersegmental membrane. These characteristics (Fig. 3AB) completely agree with T1 of Pagaronia, which also has a thin posterior expansion (Fig. 3CD).

Next, the external and internal skeletal morphology of the lateral region of T1 (i.e., the pleuron of Pagaronia and surroundings of the helmet joint region of Publilia) was examined. The T1 lateral region of Pagaronia (Fig. 4C) consists of the basic pleural elements of Paraneoptera (e.g., Kramer, 1950; Yoshizawa, 2005). The pleural suture is well developed, running from the anterodorsal corner of the pleuron to the base of the coxal socket. The pleural arm pit is invaginated from the middle of the pleural suture. The anapleural suture is evident anterior to the pleural arm pit. Internally (Fig. 4D), the pleural arm is connected to the furca via a tendon. Using these sutures and the pit as landmarks, the homology of the T1 lateral sclerites in Pagaronia can be established (Fig. 4CD: Kramer, 1950; Yoshizawa, 2005). The dorsal region of the epimeron is continuous with the tergum seamlessly (i.e., without any suture) - in agreement with the condition also observed in the other paraneopteran lineage, the Psocodea (Fig. 1D: Yoshizawa, 2005).

The homology of all structures mentioned above can be assessed in the lateral region of the helmet without any ambiguity (Fig. 4A, B). The region highlighted by a circle in Fig. 4A corresponds to the helmet joint sensu Prud'homme et al. (2011: suppl. fig. 5d). This region is the ventral end of the epimeron and thus cannot be homologous with the wing joint. Furthermore, if the helmet really is homologous with the wing, it should arise above the dorsal end of the pleural suture (e.g., Snodgrass, 1935; Matsuda, 1970; Brodsky, 1994). However, this is clearly not the case, and the helmet is continuous seamlessly with the epimeron (Fig. 4AC), as in the posterior extension of the tergum in Pagaronia.

These characteristics agree completely with the structure of the helmet in another treehopper species, Stictocephala bisonia, examined in detail by Stegmann (1998). Evidently, the treehopper's 
helmet is composed of the fundamental elements of the prothorax, and no evidence for the body plan novelty can be identified from the morphological point of view.

\section{Nymphal characters}

Prud'homme et al. (2011) provided three nymphal characters claimed to corroborate their hypothesis. First, they showed a dorsal longitudinal line dividing the developing helmet bilaterally, interpreted as a fusion line of the paired wings (suppl. fig. 2e of Prud'homme et al., 2011). However, the longitudinal line obviously represents the exuvial cleavage line because it runs from the head through $\mathrm{T} 1-\mathrm{T} 2$ to the posterior end of T3 (arrow heads in Fig. 5A). As second point, their figures show that the developing helmet extends over the T1 tergum (fig. 2c and suppl. fig. 3 of Prud'homme et al., 2011). However, the present observation clearly shows that the developing helmet extends directly from the posterior margin of the T1 tergum. The position of the T2 spiracle (arrowheads in Fig. 5BC) clearly shows that the T1-T2 intersegmental line runs beneath the developing helmet (Fig. 5C). Therefore, T1 of fig. 2c and suppl. fig. 3 in Prud'homme et al. (2011) has to be interpreted as T2, as in the case of adult morphology. Thirdly, using cross sectioned specimens they showed that the helmet develops from the bilateral primordia (fig. 2c and suppl. figs 3-4 of Prud'homme et al., 2011). Although I have not examined this developmental character, this evidence is unconvincing, because even a slight inclination of the section plane will image such a condition, even if the helmet originates from a single primordium with a straight posterior margin. As seen from the cross sections (suppl. fig. 4e-h of Prud'homme et al., 2011), the posterior margin of T1 tergum appears to have bilateral posterior extensions which are analogous to the helmet primordia. However, the posterior margins of T1 tergum is only slightly sinuate and clearly lacks the lateral extensions (Fig. 5B,C; fig. 2a and suppl. fig. 3e of Prud'homme et al., 2011). This probably provides evidence for the inclination of the section plane.

In summary, all the nymphal characteristics mentioned by Prud'homme et al. (2011) are interpreted incorrectly. 


\section{Conclusion}

As discussed above, the morphological and developmental evidence supporting the Prud'homme et al. hypothesis is a result of misinterpretation. Gene expression data was also provided by Prud'homme et al. (2011) to corroborate their morphological and developmental evidence, namely expression of the wing-patterning genes in the developing helmet. Gene expression analysis has become an important tool in studying the homology of organismal structures. However, pleiotropy and co-option are common phenomena, and non-homologous structures may have homologous gene expression (Nelson \& Martinez, 2003; Svensson, 2004). Therefore, it is widely acknowledged that the gene expression alone is insufficient to determine homology, and morphological correspondence and developmental evidence are of principal importance in identifying homology. Furthermore, Scr (Sex combs reduced: repressor of wing formation) is also expressed in the developing helmet so that gene expression data provide only modest support, if at all, for their hypothesis (Prud'homme et al., 2011; Moczek, 2011). Prud'homme et al. (2011) predicted that the formation of the helmet is due to unknown mechanisms operating downstream of Scr. However, given the lack of morphological and developmental support, co-option of the wing-forming genes to modify the T1 tergum to the helmetlike structure is more likely than their ad hoc explanation.

In conclusion, all evidence presented here shows that the treehopper's helmet should continue to be interpreted as the highly modified T1 tergum, as generally accepted (Buckton, 1903; Kramer, 1950; Hasenoehrl \& Cook, 1965; Boulard, 1973; Rietschel, 1987; Stegmann, 1988). About 50 years ago, the treehopper's helmet was also interpreted as the modified wings based on the analysis of external morphology (Richter, 1953, 1954). Interestingly, this misinterpretation was based on the erroneous homologization of a part of T2 structure with T1 (Boulard, 1973), as in the present case.

\section{Acknowledgements}

I thank the following persons: Shigeyuki Koshikawa kindly provided specimens of the treehopper species examined by Prud'homme et al. (2011). Issei Ohshima drew my attention to the Nature paper and encouraged me to draft a critique. Takuma Yoshida helped to translate French literature. A 
succinct version of this critique was first submitted to Nature. Although the submission was rejected, a reply from the Nature authors and comments from two anonymous referees helped in drafting this Opinion piece. Rolf Beutel and Niels Kristensen provided very constructive comments to the earlier manuscript. The editors of Systematic Entomology also provided helpful comments and gave me an opportunity to criticize the Nature paper.

\section{References}

Boulard, M. (1973) Le pronotum des membracides: camouflage sélectionné ou orthogenèse hypertélique? Bulletin de la Musee d'Histoire naturelle de Paris (Zoologie) 83, 145-165.

Brodsky, A. K. (1994) The Evolution of Insect Flight. Oxford Sci. Pub.

Buckton, G. B. (1903) A Monograph of the Membracidae. Lovell \& Reeve.

Burrows, M. (2007) Neural control and coordination of jumping in froghopper insects. Journal of Neurophysiology, 97, 320-330.

Cryan, J. R. (2005) Molecular phylogeny of Cicadomorpha (Insecta: Hemiptera: Cicadoidea, Cercopoidea and Membracoidea): adding evidence to the controversy. Systematic Entomology, 30, 563-574.

Grimaldi, D. \& Engel, M. S. (2005) Evolution of the insects. Cambridge Univ. Pr.

Hasenoehrl, S. G. \& Cook, P. P. (1965) A clarification of certain structures in the thoracic region of Oxyrhachis (Homoptera: Membracidae). Annals of the Entomological Society of America, 58, 219-221.

Kramer, S. (1950) The morphology and phylogeny of auchenorrhynchous Homoptera (Insecta). Illinois Biological Monographs 20, 1-111.

Matsuda, R. (1970) Morphology and evolution of the insect thorax. Memoir of the Entomological Society of Canada, 76, 1-431.

Moczek, A. P. (2011) The origins of novelty. Nature 473, 34-35.

Nelson, C. \& Martinez, P. (2003) Patterns of gene expression: homology or homocracy? Development, Genes \& Evolution, 213, 149-154. 
Prud'homme, B., Minervino, C., Hocine, M., Cande, J. D., Aouane, A., Dufour, H. D., Kassner, V. A. \& Gompel, N. (2011) Body plan innovation in treehoppers through the evolution of an extra wing-like appendage. Nature, 473, 83-86.

Richter, L. (1953) El apéndice pronotal en los Membracidos. Lozania, 7, 1-4.

Richter, L. (1954) Membracidae Colombianae. Caldasia, 6, 269-380.

Rietschel, S. (1987) Autotomie des Pronotum bei Buckelzirpen (Homoptera: Membracidae). Entomologia Generalis, 12, 209-220.

Snodgrass, R. E. (1935) Principle of insect morphology. McGraw-Hill.

Stegmann, U. (1998) An exaggerated trait in insects: The prothoracic skeleton of Stictocephala bisonia (Homoptera: Membracidae). Journal of Morphology, 238, 157-178.

Svensson, M. E. (2004) Homology and homocracy revisited: gene expression patterns and hypothesis of homology. Development, Genes \& Evolution, 214, 418-421.

Yoshizawa, K. (2005) Morphology of Psocomorpha (Psocodea: 'Psocoptera). Insecta matsumurana, new series, 62, 1-44.

Yoshizawa, K. (2011) Monophyletic Polyneoptera recovered by wing base structure. Systematic Entomology, 36, 377-394.

Yoshizawa, K. \& Saigusa, T. (2001) Phylogenetic analysis of paraneopteran orders (Insecta: Neoptera) based on forewing base structure, with comments on monophyly of Auchenorrhyncha (Hemiptera). Systematic Entomology, 26, 1-13.

\section{Appendix: Materials and methods}

Adults and various nymphal stages of Publilia modesta were collected at Research Park, Madison, Wisconsin, USA on July 10, 2011. Adults of Pagaronia sp. were collected at Hokkaido University, Sapporo, Hokkaido, Japan on June 21, 2011. All specimens were freshly killed and stored in 80\% ethanol. Observations were made in glycerol using Olympus SZX16 stereoscopic microscope. The longitudinal sections in Fig. 3 were made by hand using a razor blade. For detailed observations of endo- and exoskeletons (Fig. 4), specimens were soaked with 10\% KOH. Photographs were taken by Ricoh Caplio R7 using digiscoping method. 


\section{Figure captions}

Fig. 1. A, B, Publilia modesta (helmet removed), dorsal (A: reproduced from Prud'homme et al.'s suppl. fig. 1b) and lateral views (B: reproduced from fig. 2e). C, D, T1-T3 of the barklouse, Longivalvus nubilus (Psocodea), dorsal (C) and lateral views (D: the arrowhead indicates T2 spiracle and the sclerite with asterisk is homologous with the Prud'homme's wing hinge sclerite) (reproduced from Yoshizawa, 2005). The anterior lobe of the T2 scutum is shaded.

Fig. 2. The wing hinge sclerite sensu Prud'homme et al. (2011) (white arrow head). The sclerite is located posterior to the helmet and, above the sclerite, the mesothoracic spiracle (sp2) can be seen.

Fig. 3. Longitudinal sections of Publilia (A, B) and Pagaronia (C, D). Dotted thin lines indicate the dorsal longitudinal muscles. Thick continuous lines in B, D indicate sclerotized structure, and thin continuous lines indicate membranous structure.

Fig. 4. The lateral structures of the prothorax of Publilia (A, B) and Pagaronia (C, D). A, C, anterolateral view (head comes to the left); B, D anterior view, showing exo- and endoskeleton.

Fig. 5. First instar nymph of Publilia, dorsal (A) and lateral (B, C) views. Abbreviations: em=epimeron; es=episternum; $\mathrm{sp}=$ spiracle 
"T1" of Prud' homme
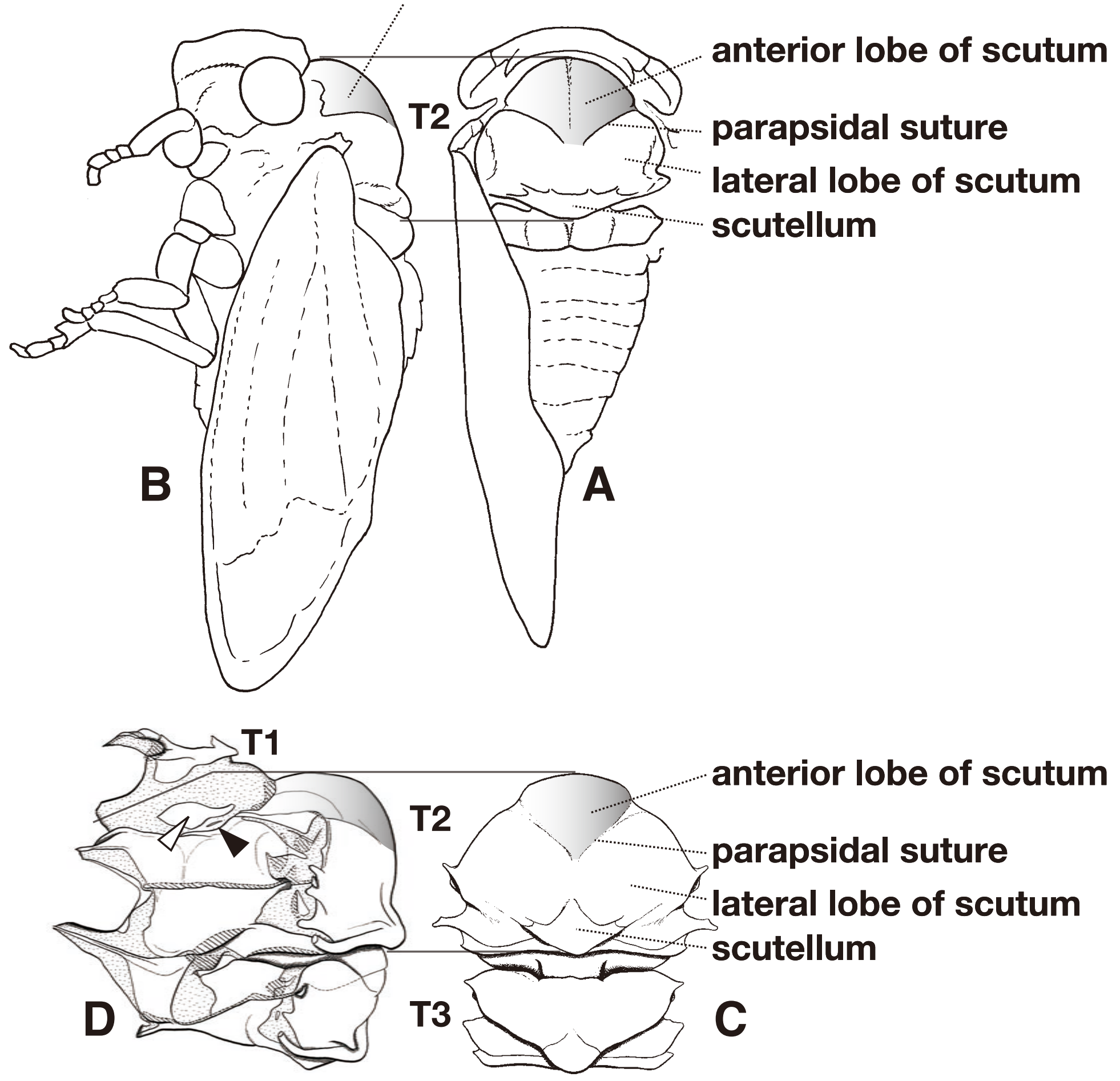


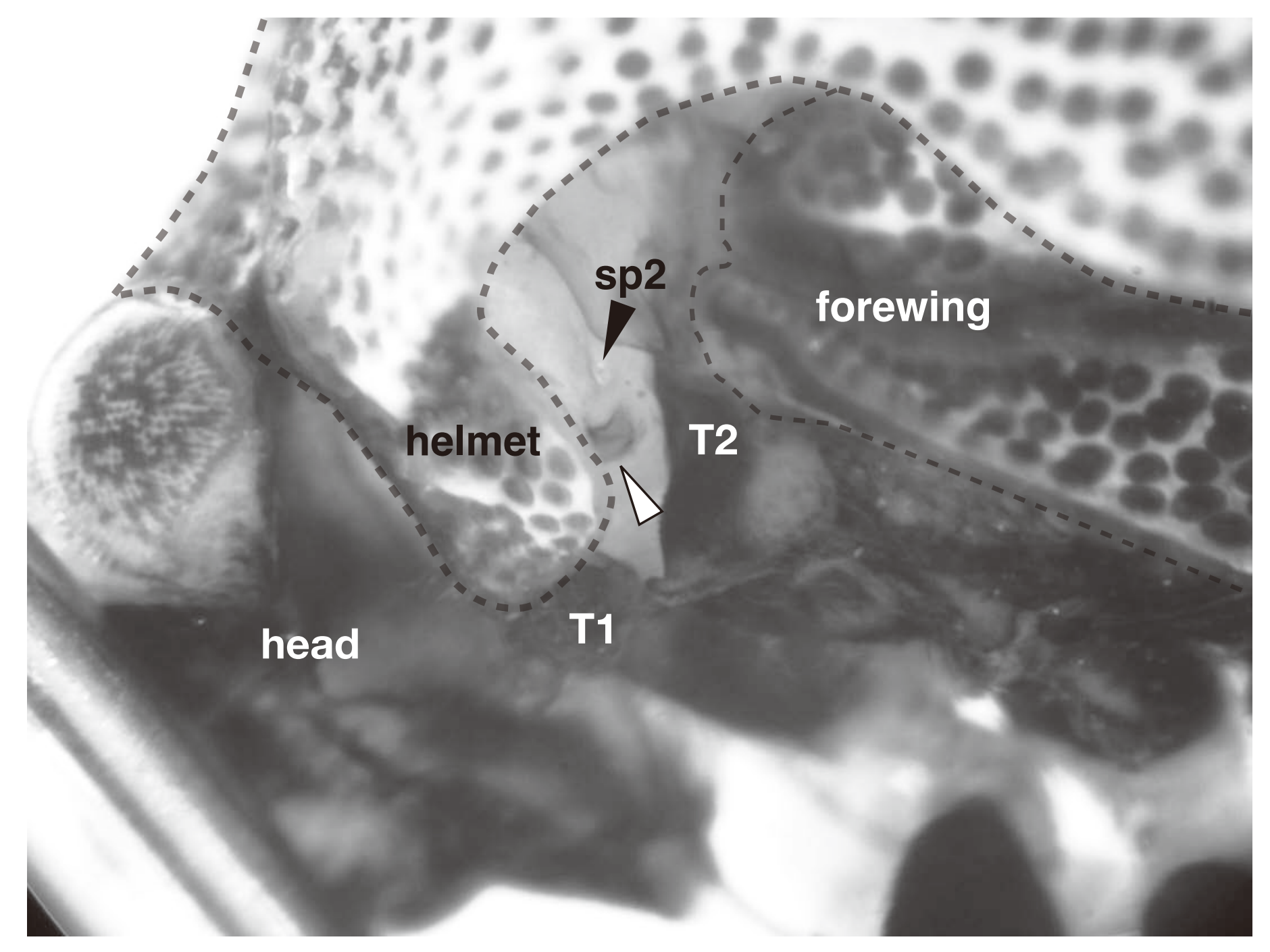



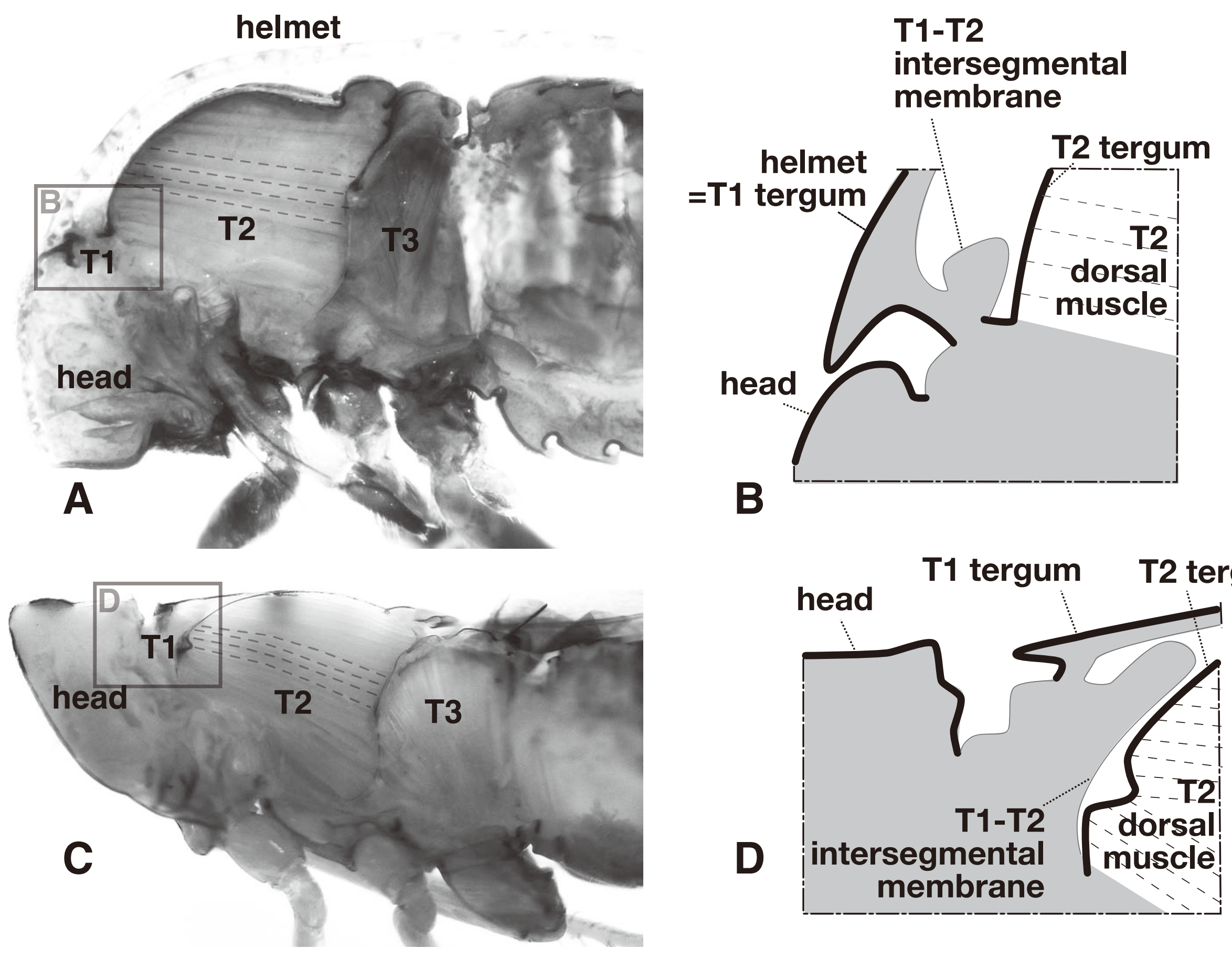

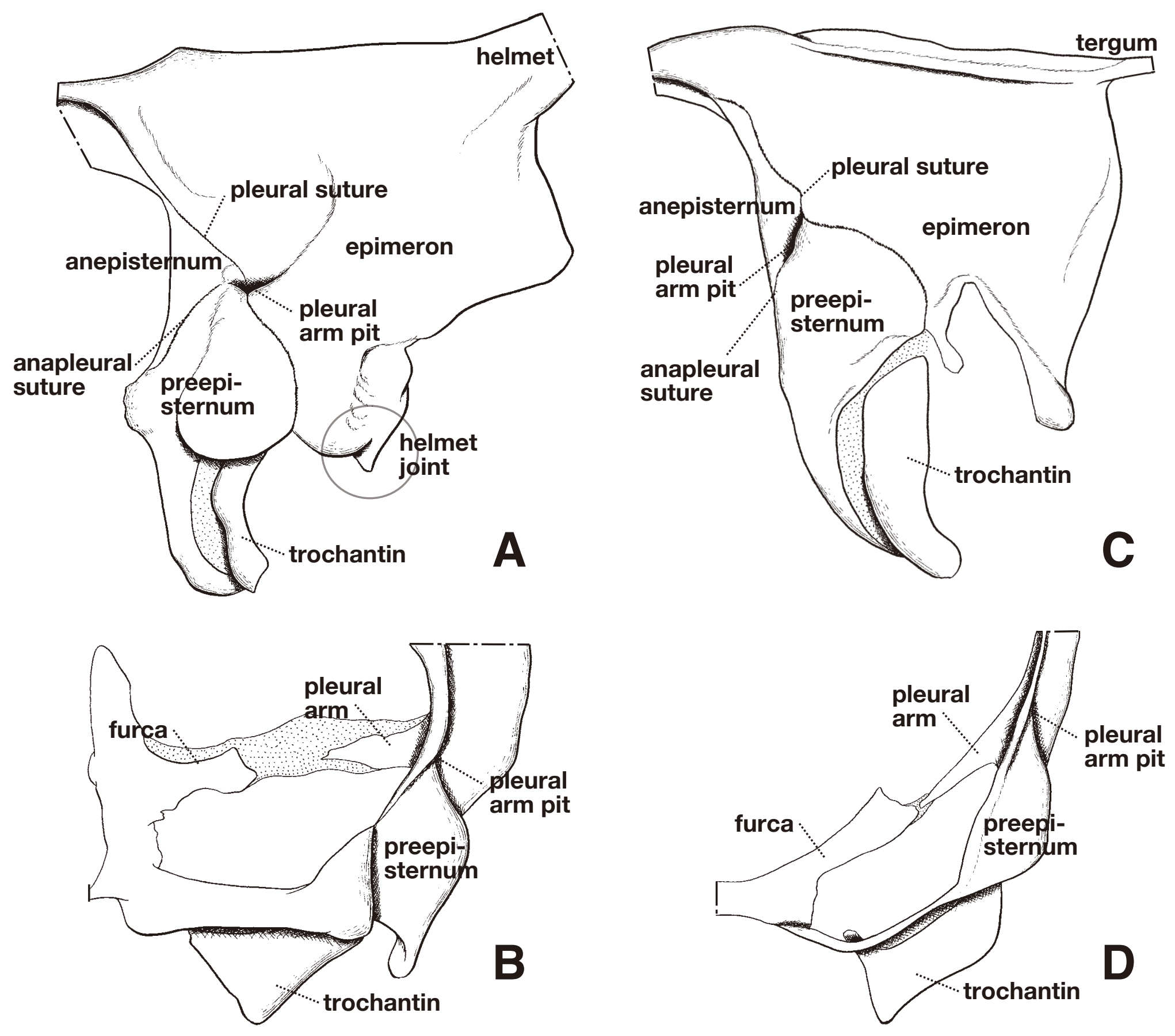


\section{- head head}

$=-\mathrm{T} 1-\mathrm{T} 2$ intersegment

$\div \mathrm{T} 1$

T1

T2

; 3

A

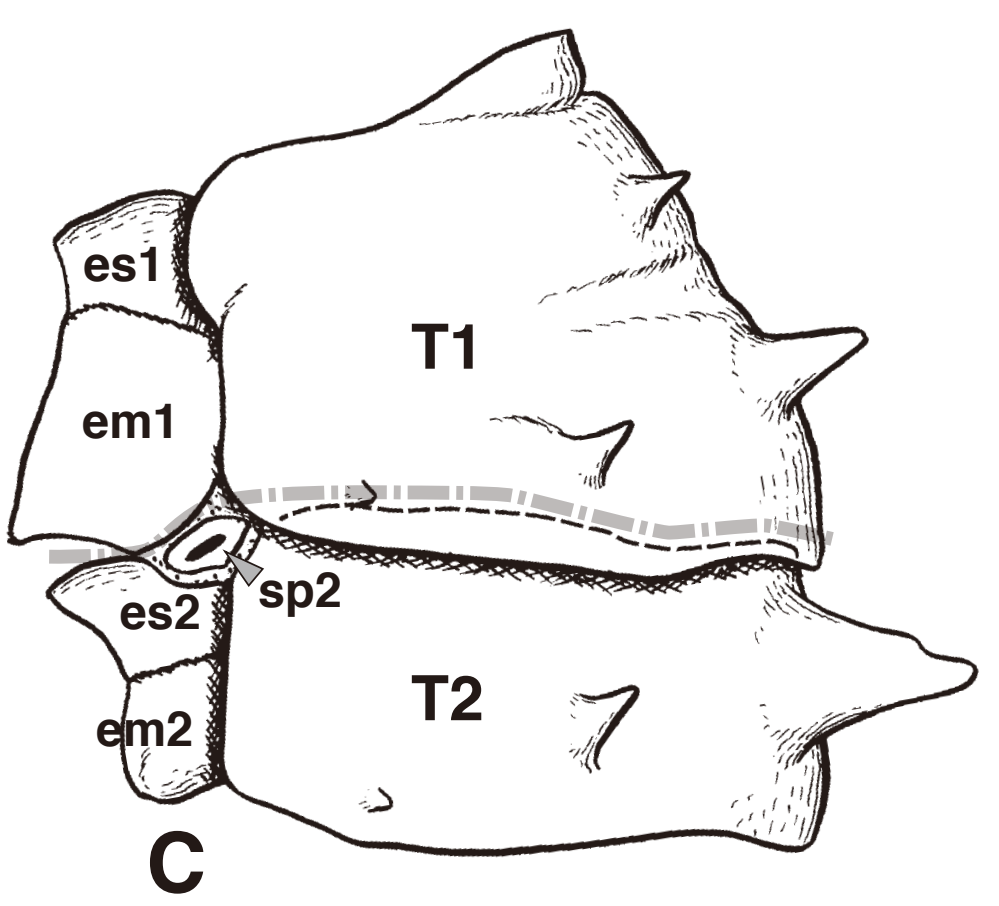

